\title{
Behavior of metals Induced by magnetic pulse loading
}

\author{
Atroshenko Svetlana ${ }^{1, a}$, Morozov Viktor ${ }^{2}$, Gribanov Denis $^{1}$, Lukin Anton $^{2}$, and Petrov Yuriy ${ }^{1}$ \\ ${ }^{1}$ IPME RAS, V.O., Bolshoy, 61, St. Petersburg 199178, Russia \\ ${ }^{2}$ Saint Petersburg state university, 7-9, Universitetskaya nab., St. Petersburg 199034, Russia
}

\begin{abstract}
The investigation of copper and aluminum ring samples was carried out using magnetic pulse loading. Two modifications of the magnetic pulse technique were used. They were based on a GKVI-300 high-voltage narrow-pulse generator Morozov et al. (2011) [1]. It is possible using these two approaches to decrease the period of the harmonic load up to $100 \mathrm{~ns}$. The study of fracture surfaces of aluminum and copper samples after the test was carried out on an optical microscope AxioObserver-Z1-M in a dark field, and study of the cross sections structure - in the bright field or C-DIC. The structure has been studied in cross sections after appropriate etching. Grain size and the number of pores on the surface of cross sections were determined after etching. Microhardness was measured on a PMT-3 device with a load of $20 \mathrm{~g}$. The optical micrographs of aluminum demonstrate that the long pulse causes almost fully ductile fracture. In the case of the short pulse, the number of fibers decreases: the fracture surface exhibits the signs of both ductile cup fracture and brittle crystalline fracture with cracks, which are sometimes rather deep. In addition, the short pulse results in twinning, which seems surprising for aluminum featuring a high stacking fault energy. It is seen that under short loading dynamic recrystallization occurs. As for copper samples before loading they were in the form of single crystal and after loading their structure due to dynamic recrystallization consists of small grain. The specimen with notch has more developed dynamic recrystallization shear bands.
\end{abstract}

\section{Introduction}

Zhang and Ravi-Chandar [2-5] reported recent experimental data for high-speed tangential extension to rupture of thin metallic rings by a magnetic pulse technique. Electro-magnetic loading provided radial expansion rates of the ring in the range $80-200 \mathrm{~m} / \mathrm{s}$ or strain rates on the order of $10^{4} \mathrm{~s}^{-1}$. Necking and fragmentation were recorded with a high-resolution streak camera. It was shown that the ring fails for a time much shorter than the first period of current oscillations in it. Fragmentation lasted less than $20 \mu \mathrm{s}$. The radius of the ring as a function of time was determined photographically; the velocity, by differentiating this function. The ring rapidly picked up a speed of $100-250 \mathrm{~m} / \mathrm{s}$ and then slowed down when the current decreased and the energy dissipated as a result of plastic deformation.

Strain rate $\varepsilon^{\prime}=r^{\prime} / r$ was roughly estimated as falling into the interval $(0.5-1.3) \times 10^{4} \mathrm{~s}^{-1}$. In uniformly deforming regions of the ring, the strain was found to never exceed a necking threshold. An increase in the crosssectional area of the sample considerably increased the strain preceding the onset of strain localization. The strain before localization did not depend on the strain rate. In samples with a cross-sectional area ratio of more than 5 the strain localized in the form of shear bands. As the sample grew in size, the strain distribution became more uniform. It was shown that polymeric coatings slightly influence the onset of necking at high-rate deformation. Tubes exhibited uniform expansion to a critical strain with

\footnotetext{
${ }^{a}$ Corresponding author: author@email .org
}

subsequent formation of shear bands and failure at the sites of their intersection. Nomenclature is given in Table 1.

In this work, the approach suggested in Morozov et al. (2011) [1] is elaborated.

\section{Experimental technique}

Two modifications of the magnetic pulse technique were used. They were based on a GKVI-300 high-voltage narrow-pulse generator providing voltage amplitudes of $30-300 \mathrm{kV}$ [1]. They could realized a sinusoidal load with a period of $7.5 \mu \mathrm{s}$ and with a period of $1 \mu \mathrm{s}$.

The loading scheme is shown in Fig. 1. A current passing through a solenoid on which a coaxial ring sample is placed induces a current in the sample, and interaction between these currents gives rise to a repulsion force between the ring and solenoid. The solenoid was made of a copper wire $1 \mathrm{~mm}$ in diameter. It had five turns and a diameter of $25 \mathrm{~mm}$. The current through the solenoid was measured by Rogowski coil and displayed on digital oscilloscope, and information from the oscilloscope was written in electronic format. When the sample coaxially placed on solenoid broke, photodiode recorded a flash indicating the instant of rupture.

The study of fracture surfaces of aluminum and copper samples after the test was carried out on an optical microscope Axio-Observer-Z1-M in a dark field, and study the structure of cross sections - in the bright field or C-DIC. The structure has been studied in cross sections after appropriate etching. Grain size and the number of pores on the surface of cross sections were determined after etching. Microhardness was measured on a PMT-3 
Table 1. Nomenclature.

\begin{tabular}{|c|c|}
\hline Symbol & Title \\
\hline $\mathrm{T}$ & the period of the harmonic load, $\mu \mathrm{s}$ \\
\hline $\mathrm{S}$ & is the shear area at the fracture surface \\
\hline $\mathrm{d}$ & sample diameter \\
\hline $\mathrm{D}$ & grain size \\
\hline $\mathrm{n}$ & number of pores in the area of $400 \mu \mathrm{m}^{2}$ \\
\hline
\end{tabular}

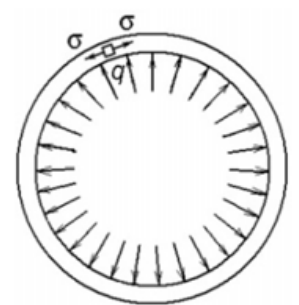

Figure 1. Sample loading scheme: q, load; $\sigma$, tensile stress [1].
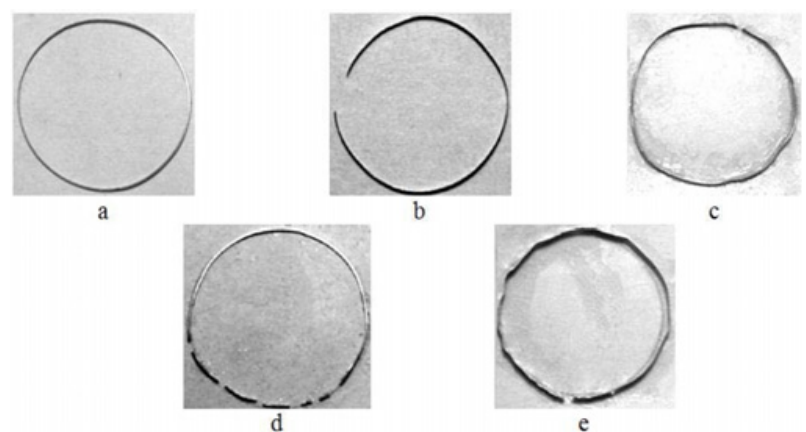

Figure 2. View of the sample: (a) before loading; (b) fracture at a threshold energy, $T=7.4 \mu \mathrm{s}$; (c) fracture at a threshold energy, $\mathrm{T}=1 \mu \mathrm{s}$; (d) fracture at an energy far exceeding the threshold, $\mathrm{T}=7.4 \mu \mathrm{s}$; and (e) fracture of the sample made of aluminum foil $0.03 \mathrm{~mm}$ thick, $\mathrm{T}=1 \mu \mathrm{s}$ [1]

device with a load of $20 \mathrm{~g}$. The ductile fracture surface was matt gray with characteristic "fibers." The brittle fracture surface is seemingly crystalline without noticeable signs of plastic deformation.

Amount B (\%) of the ductile component on the fracture surface was determined by the formula (1)

$$
B=100-X
$$

given in the State Standard ( $X$ is the percentage of the brittle component on the fracture surface). The surface area of the brittle component was measured on the photograph.

Test rings were made of aluminum alloy and had an inner diameter of $28 \mathrm{~mm}$. Rings to be tested with long-period voltages were $0.11-0.40 \mathrm{~mm}$ thick and $0.5-1.0 \mathrm{~mm}$ wide, and those subjected to short-period voltages were $0.11 \mathrm{~mm}$ in thickness and $1.0 \mathrm{~mm}$ in width. It was investigated also rings made of foil $0.03 \mathrm{~mm}$ thick and 1.5-2.0 mm wide.

\section{Results and discussion}

Figure 2 shows the samples in initial state and those having been subjected to loading under different conditions. Both for the 7.4- $\mu$ s-long pulse (Fig. 2b) and for the 1.0- $\mu$ s-long
Table 2. Percentage of fibers on the fracture surface of aluminum.

\begin{tabular}{|c|l|l|l|}
\hline Number & Loading technique & $\mathbf{T}, \boldsymbol{\mu} \mathbf{s}$ & $\mathbf{S}, \boldsymbol{\%}$ \\
\hline 1 & Magnetic pulse loading & 7.5 & 98.2 \\
\hline 2 & The same & 1 & 91.5 \\
\hline 3 & Light gas gun & 1.3 & 94.03 \\
\hline
\end{tabular}

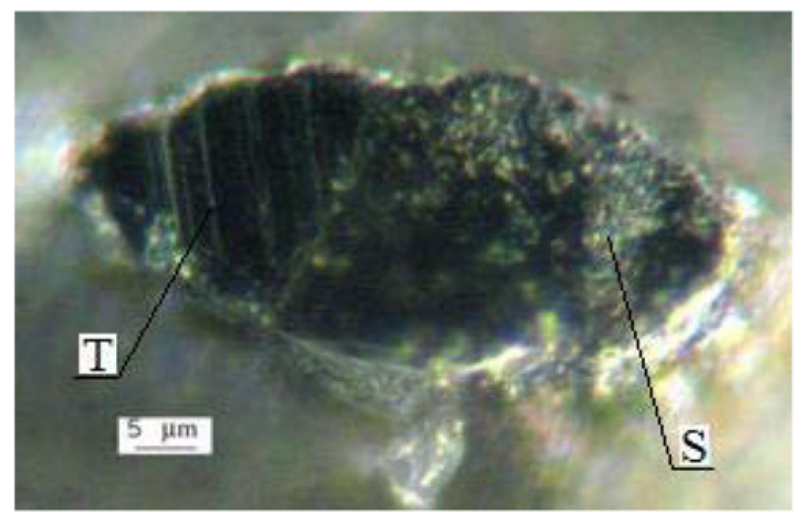

Figure 3. Fracture surface of the sample subjected to $1-\mu \mathrm{m}$-wide loading pulses: $\mathrm{S}-$ shear area and $\mathrm{T}-$ twins.

Table 3. Font styles for a reference to a journal article.

\begin{tabular}{|l|l|l|l|l|l|l|}
\hline Material & $\begin{array}{l}\mathbf{T}, \\
\boldsymbol{\mu} \mathbf{s}\end{array}$ & $\begin{array}{l}\mathbf{d ,} \\
\mathbf{m m}\end{array}$ & $\begin{array}{l}\mathbf{h \times ~ b}, \\
\boldsymbol{\mu m}^{2}\end{array}$ & $\begin{array}{l}\mathbf{H V}, \\
\mathbf{M P a}\end{array}$ & $\begin{array}{l}\mathbf{D}, \\
\boldsymbol{\mu m}\end{array}$ & $\begin{array}{l}\mathbf{n}, \\
\mathbf{1 / 4 0 0} \\
\boldsymbol{\mu} \mathbf{m}^{\mathbf{2}}\end{array}$ \\
\hline $\mathrm{Al}$ & 7.5 & 28 & $193.5 \times 10^{3}$ & 1098 & 1.2 & 121 \\
\hline $\mathrm{Al}$ & 1 & 28 & $68.4 \times 10^{3}$ & 1202 & 3.0 & 70 \\
\hline $\mathrm{Al}$ & 0.08 & 28 & & 303.3 & 1.05 & 36 \\
\hline $\mathrm{Al}$ initial & & 28 & $120 \times 10^{3}$ & 135.76 & 4.6 & 53 \\
\hline $\mathrm{Cu}$ & 1 & 28 & $29.9 \times 10^{3}$ & 405.4 & 2.5 & 96 \\
\hline $\mathrm{Cu}$ notch & 1 & 28 & $75.8 \times 10^{3}$ & 705.8 & 0.8 & 380 \\
\hline $\mathrm{Cu}$ notch & 0.08 & 28 & & 1070.5 & 0.84 & 111 \\
\hline $\mathrm{Cu}$ initial & & 28 & $15 \times 10^{3}$ & 142.46 & & 282 \\
\hline
\end{tabular}

pulse (Fig. 2c), rupture is seen to occur at the same site; the only difference is that many necks are observed in the latter case. When the energy of the 7.4- $\mu$ s-long pulse exceeds the threshold value, fragmentation becomes more intense. When the foil sample is loaded by the 1.0- $\mu$ s-long pulse (Fig. 2e), fragmentation is accompanied by necking.

The measured data for the ductile component of fracture are given in Table 2. The notation in Table 2 is the following: $\mathrm{T}$ is the pulse width, $\mathrm{S}$ is the shear area at the fracture surface. As the pulse gets shorter, the fraction of fibers in fracture decreases monotonically; that is, the samples embrittle.

For comparison, Table 2 gives experimental values of $\mathrm{T}$ and $\mathrm{S}$ for aluminum loaded by an air-gas impact machine with an intermediate pulse width of $1.3 \mu \mathrm{m}$. The results of fracture surface examination are given in Table 2 . In the case of the long pulse, fracture is seen to be mostly ductile; that is, the samples are more ductile than for the short pulse. The shortening of the current period the share area on the fracture surface decreases monotonically, i.e. samples become more brittle.

The optical micrographs demonstrate that the long pulse causes almost fully ductile fracture. In the case 


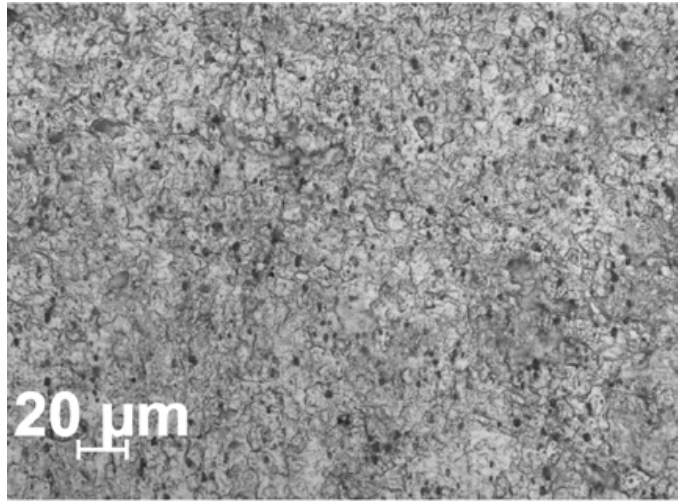

a

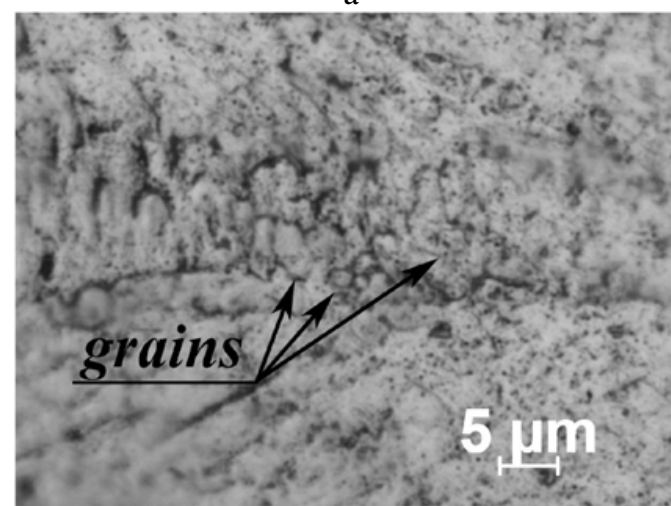

$\mathrm{b}$

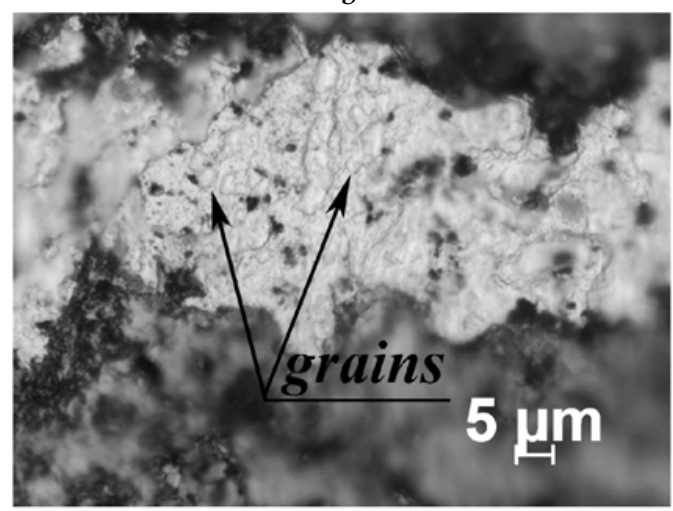

c

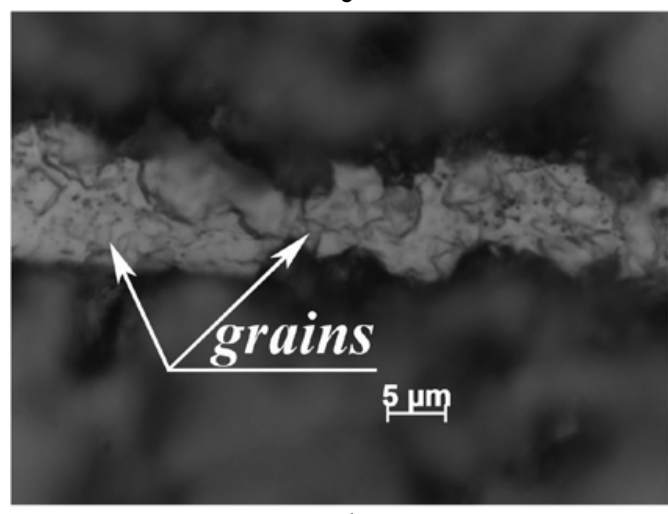

d

Figure 4. The structure of aluminum: (a) - in the initial state, (b) - after loading with the period $\mathrm{T}=7.5 \mu \mathrm{s}\left(\mathrm{S}=0.19 \mathrm{~mm}^{2}\right)$;

(c) - after loading with the period $\mathrm{T}=1 \mu \mathrm{s}\left(\mathrm{S}=0.07 \mathrm{~mm}^{2}\right)$; (d) - after loading with the period $\mathrm{T}=0,08 \mu \mathrm{s}\left(\mathrm{S}=0.02 \mathrm{~mm}^{2}\right)$.

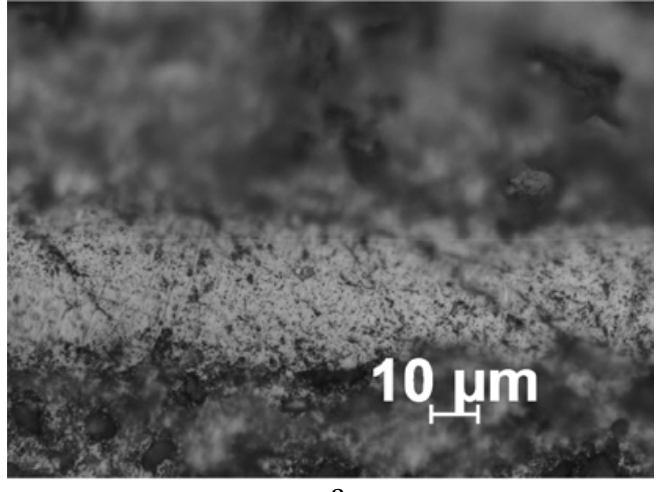

a

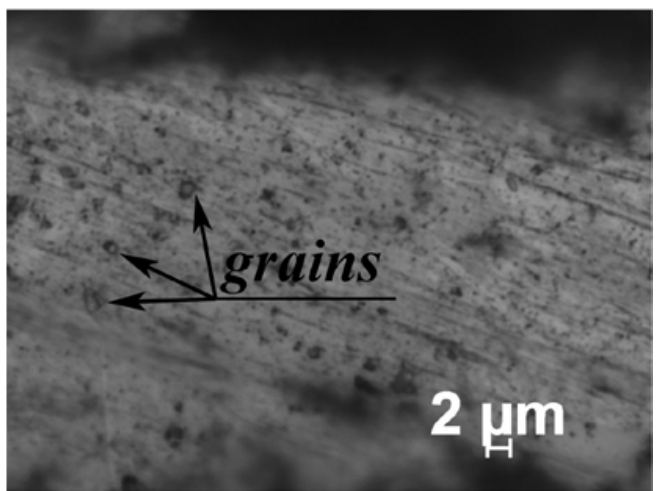

b

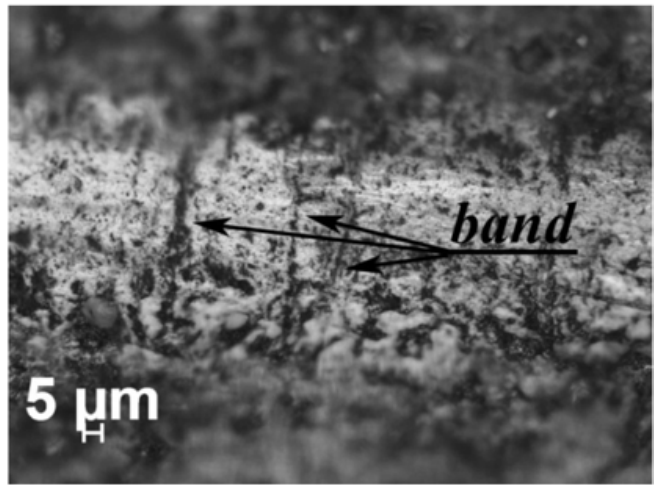

C

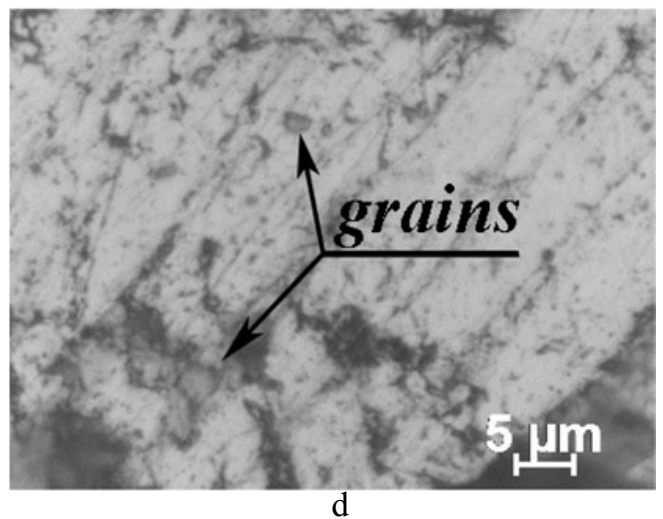

Figure 5. Structure of copper: $\mathrm{a}$ - in the initial state, $\mathrm{b}$ - nucleation of new grains during dynamic recrystallization after loading with the period $\mathrm{T}=1 \mu \mathrm{s}\left(\mathrm{S}=0.03 \mathrm{~mm}^{2}\right)$; $\mathrm{c}$ - shear bands in a sample with a notch after loading with period $\mathrm{T}=1 \mu \mathrm{s}\left(\mathrm{S}=0.01 \mathrm{~mm}^{2}\right)$, $\mathrm{d}$ - nucleation of new grains during dynamic recrystallization after loading with the period $\mathrm{T}=0.08 \mu \mathrm{s}\left(\mathrm{S}=0.02 \mathrm{~mm}^{2}\right)$. 
of the short pulse, the shear area decreases: the fracture surface exhibits the signs of both ductile cup fracture and brittle crystalline fracture with cracks, which are sometimes rather deep. In addition, the short pulse results in twinning (Fig. 3), which seems surprising for aluminum alloys featuring a high stacking fault energy. Twinning is a typical deformation mechanism at fast loading of alloys with a low or medium stacking fault energy. As for materials with a high stacking fault energy, they twin only under a high load (above the twinning threshold) or at a very high rate of loading.

Characteristics of the samples and results are summarized in Table 3, where $\mathrm{T}$ - the period of oscillation of the current in the coil; $\mathrm{d}$ - ring diameter; $\mathrm{S}=\mathrm{h} \times \mathrm{b}-$ cross-section of the sample; $\mathrm{D}$ - grain size; $\mathrm{n}$ - number of pores in the area of $400 \mu \mathrm{m}^{2}$; HV - microhardness.

Figure 4 shows the structure of aluminum samples at initial state and after loading with different periods and different cross-section (scale factor).

It is seen the dynamic recrystallization - the formation of new small grains for short-time loading. The highest degree of dynamic recrystallization is in the samples of aluminum with longer duration of loading and a maximum cross-section (scale factor). Aluminum samples after loading showed a greater tendency to porosity with increasing loading period compared with baseline.

Porosity in copper after magnetic pulse loading was below than in the initial state. In addition, with increasing loading duration the samples had the generation of multiple cracks.

Figure 5 shows the structure of copper in the initial state and after the magnetic pulse loading.

The copper sample before loading was a single crystal, and after loading as a result of dynamic recrystallization small grains appear with the size $-0.7-2.5 \mu \mathrm{m}$. And the more advanced dynamic recrystallization is in a sample with a higher period of the current - smaller grains are here. Furthermore, in the sample with a notch there are large amount of shear bands.

\section{Conclusions}

1. It was developed and tested a magnetic pulse method with simultaneous photographic registration of the moment of fracture metallic ring samples with short (about $1 \mu \mathrm{s})$ pulse tensile influences.

2. It was found that shortening the exposure time leads to the fracture of the samples. Samples become more brittle. Dynamic recrystallization processes and the formation of cracks observed in the aluminum samples, whereas twinning and shear bands formation occur in copper.

Work was financially supported by RFBR grants 14-01-00814, 12-01-91154-NSFC, RFBR 13-01-00335, No.25 RAS Presidium program and FP7 EU MARIE CURIE Project TAMER No. 610, 547.

\section{References}

[1] V.A. Morozov, Yu.V. Petrov, A.A. Lukin, V.M. Kats, A.G. Udovik, S.A. Atroshenko, D.A. Gribanov, G.D. Fedorovsky, Technical Physics 56, (2011) 797-802

[2] O.H. Zhang and K. Ravi Chandar, Int. J. Fract. 142, (2006) 183-217

[3] O.H. Zhang and K. Ravi Chandar, Int. J. Fract. 150, (2008) 3-36

[4] O.H. Zhang and K. Ravi Chandar, Int. J. Fract. 155, (2009) 101-118

[5] O.H. Zhang and K. Ravi Chandar, Int. J. Fract. 163, (2010) 41-65 